\title{
Effects of an alveolar recruitment maneuver on subdural pressure, brain swelling, and mean arterial pressure in patients undergoing supratentorial tumour resection: a randomized crossover study
}

\section{Effets d'une manœuvre de recrutement alvéolaire sur la pression sous-durale, l'œdème cérébral et la tension artérielle moyenne chez les patients subissant une résection de tumeur sus-tentorielle: une étude croisée randomisée}

\author{
Alana M. Flexman, MD, FRCPC • Peter A. Gooderham, MD, FRCSC • \\ Donald E. Griesdale, MD, MSc, FRCPC • Ruth Argue, BScN • Brian Toyota, MD, \\ FRCSC
}

Received: 22 August 2016/Revised: 11 January 2017/Accepted: 13 March 2017/Published online: 24 March 2017

(C) Canadian Anesthesiologists' Society 2017

\begin{abstract}
Purpose Although recruitment maneuvers have been advocated as part of a lung protective ventilation strategy, their effects on cerebral physiology during elective neurosurgery are unknown. Our objectives were to determine the effects of an alveolar recruitment maneuver on subdural pressure (SDP), brain relaxation score (BRS), and cerebral perfusion pressure among patients undergoing supratentorial tumour resection.
\end{abstract}

A. M. Flexman, MD, FRCPC ( $\triangle)$.

D. E. Griesdale, MD, MSc, FRCPC

Department of Anesthesiology, Pharmacology and Therapeutics, Vancouver General Hospital, University of British Columbia, Room 2449 JPP 899 West 12th Avenue, Vancouver,

BC V5Z 1M9, Canada

e-mail: alana.flexman@vch.ca

P. A. Gooderham, MD, FRCSC - B. Toyota, MD, FRCSC Division of Neurosurgery, Department of Surgery, University of British Columbia, Vancouver, BC, Canada

R. Argue, $\mathrm{BScN}$

Vancouver Coastal Health Research Institute, Vancouver, BC,

Canada

Present Address:

R. Argue, BScN

Wellcome Trust HRB Clinical Research Facility, St. James's

Hospital, H\&H Building, Level 2, Dublin 8, Ireland
Methods In this prospective crossover study, patients scheduled for resection of a supratentorial brain tumour were randomized to undergo either a recruitment maneuver $(30 \mathrm{~cm}$ of water for $30 \mathrm{sec})$ or a "sham" maneuver (5 cm of water for $30 \mathrm{sec}$ ), followed by the alternative intervention after a 90-sec equilibration period. Subdural pressure was measured through a dural perforation following opening of the cranium. Subdural pressure and mean arterial pressure (MAP) were recorded continuously. The blinded neurosurgeon provided a BRS at baseline and at the end of each intervention. During each treatment, the changes in SDP, BRS, and MAP were compared.

Results Twenty-one patients underwent the study procedure. The increase in SDP was higher during the recruitment maneuver than during the sham maneuver (difference, $3.9 \mathrm{mmHg}$; 95\% confidence interval [CI], 2.2 to 5.6; $P<0.001)$. Mean arterial pressure decreased further in the recruitment maneuver than in the sham maneuver (difference, $-9.0 \mathrm{mmHg} ; 95 \% \mathrm{CI},-12.5$ to -5.6; $P<0.001)$. Cerebral perfusion pressure decreased $14 \mathrm{mmHg}(95 \% \mathrm{CI}, 4$ to 24) during the recruitment maneuver. The BRS did not change with either maneuver. Conclusion Our results suggest that recruitment maneuvers increase subdural pressure and reduce cerebral perfusion pressure, although the clinical importance of these findings is thus far unknown. This trial was registered with ClinicalTrials.gov, NCT02093117. 


\section{Résumé}

Objectif Bien que les manœuvres de recrutement aient été défendues dans le cadre de stratégies de ventilation protectrices des poumons, leurs effets sur la physiologie cérébrale pendant une neurochirurgie non urgente sont inconnus. Nos objectifs étaient de déterminer les effets d'une manœuvre de recrutement alvéolaire sur la pression sous-durale (PSD), le score de relaxation cérébrale (SRC) et la pression de perfusion cérébrale chez les patients subissant une résection de tumeur sus-tentorielle.

Méthode Dans cette étude croisée prospective, les patients devant subir une résection d'une tumeur cérébrale sus-tentorielle ont été randomisés à recevoir soit une manouvre de recrutement $(30 \mathrm{~cm}$ d'eau pendant $30 \mathrm{sec}$ ) ou une manceuvre fictive (5 cm d'eau pendant 30 sec), suivie de l'intervention alternative après une période d'équilibration de $90 \mathrm{sec}$. La pression sous-durale a été mesurée via une perforation durale réalisée après l'ouverture du crâne. La pression sous-durale et la tension artérielle moyenne (TAM) ont été enregistrées en continu. Le neurochirurgien a donné, en aveugle, un SRC au début et à la fin de chaque intervention. Pendant chaque traitement, les changements de PSD, de SRC, de TAM et de fréquence cardiaque ont été comparés.

Résultats Vingt-et-un patients ont subi l'intervention à l'étude. L'augmentation de la PSD était plus élevée pendant la manouvre de recrutement que durant la manæuvre fictive (différence, 3,9 $\mathrm{mmHg}$; intervalle de confiance [IC] $95 \%$, 2,2 à 5,6; $P<0,001)$. La tension artérielle moyenne a davantage diminué pendant la manœuvre de recrutement que pendant la manouvre fictive (différence, $-9,0 \mathrm{mmHg}$; IC $95 \%,-12,5$ à -5,6; $P<0,001)$. La pression de perfusion cérébrale a baissé de $14 \mathrm{mmHg}$ (IC $95 \%, 4$ à 24) pendant la manouvre de recrutement. Le SRC n'a pas changé avec l'une ou l'autre mancuvre.

Conclusion Selon nos résultats, les manœuvres de recrutement augmenteraient la pression sous-durale et réduiraient la pression de perfusion cérébrale, bien que l'importance clinique de ces résultats soit encore inconnue à ce jour. Cette étude a été enregistrée au ClinicalTrials.gov, NCT02093117.

Alveolar recruitment maneuvers involve the application of high continuous positive airway pressure at regular intervals to improve oxygenation, optimize alveolar recruitment, and minimize sheer stress caused by repeated opening of collapsed alveoli. ${ }^{1}$ Lung protective ventilation using a combination of lower tidal volumes, increased positive end-expiratory pressure, and regular recruitment maneuvers reduces mortality in critically ill patients with acute respiratory distress syndrome. ${ }^{2,3}$ Recently, lung protective ventilation has also been shown to reduce complications in elective patients undergoing abdominal surgery. ${ }^{4}$ As neurosurgical patients represent a high-risk population for respiratory failure, ${ }^{5}$ lungprotective ventilation represents a potential beneficial intervention in this population.

Although these maneuvers may improve respiratory outcomes, the effect of high airway pressures on intracranial and cerebral perfusion pressure in elective neurosurgical patients is not known and may be detrimental. Previous studies on brain-injured patients in the intensive care unit have shown increased intracranial pressure and reduced cerebral perfusion pressure during recruitment maneuvers. ${ }^{6,7}$ Although evidence supporting the benefits of lung protective ventilation during surgical procedures is mounting, we have not yet defined the effect of high levels of continuous airway pressure on the cerebral physiology in neurologically intact patients undergoing open neurosurgical procedures. Our primary objective was to determine the effect of an intraoperative alveolar recruitment maneuver on subdural pressure (SDP), a surrogate measure of intracranial pressure, in neurosurgical patients undergoing supratentorial tumour resection. Our secondary objectives were to determine the effect of an intraoperative alveolar recruitment maneuver on 1) surgeon-assessed intraoperative brain relaxation score (brain bulk score) and 2) cerebral perfusion pressure.

\section{Methods}

This study was conducted following approval from the Clinical Research Ethics Board of the University of British Columbia (Protocol H14-00009, approved March 24, 2014). The trial was performed at Vancouver General Hospital, a tertiary care teaching hospital located in Vancouver, BC. The study was registered with ClinicalTrials.gov (NCT02093117)

Study design

Following written informed consent, participants were enrolled in this prospective crossover study and randomly allocated to undergo either a recruitment maneuver $(30 \mathrm{~cm}$ of water continuous airway pressure for $30 \mathrm{sec}$ ) or a "sham" recruitment maneuver $(5 \mathrm{~cm}$ of water for $30 \mathrm{sec})$ (Fig. 1). After a brief 90 -sec equilibration period-to 


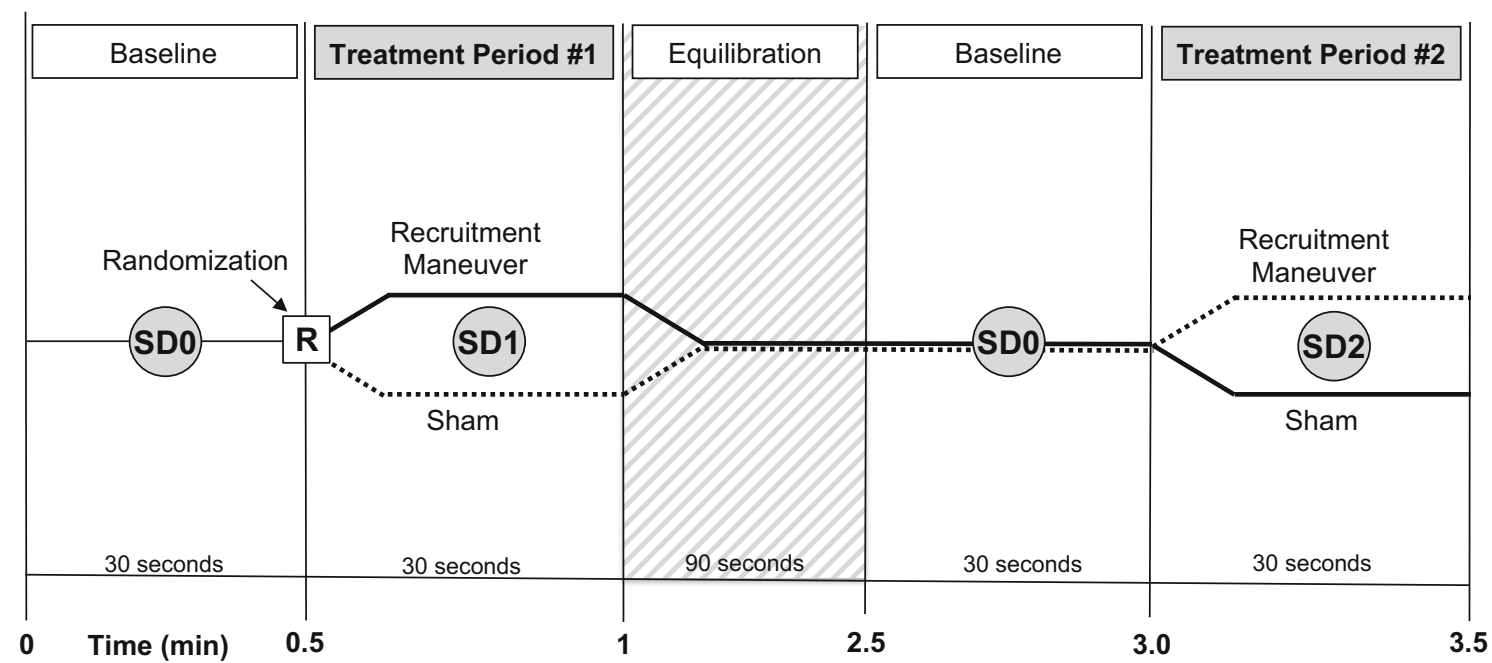

Fig. 1 The randomized crossover study design involved two treatment periods of either a recruitment maneuver of $30 \mathrm{~cm} \mathrm{H} 2 \mathrm{O}$ for $30 \mathrm{sec}$, or a sham procedures of $5 \mathrm{~cm} \mathrm{H}_{2} \mathrm{O}$ for $30 \mathrm{sec}$, separated by

ensure normalization of carbon dioxide levels to baselinefollowed by a $30-\mathrm{sec}$ baseline measurement, the participant then underwent the alternative intervention. Once the second maneuver and measurements were complete, the study was terminated and the surgical procedure proceeded as planned. Simple randomization of the treatment order was achieved using an internet-based program (www. sealedenvelope.com). The research assistant (R.A.) recruited, enrolled, and randomized the participants.

\section{Study population}

Adult patients who were American Society of Anesthesiologists' class I-III and scheduled for craniotomy for resection of a supratentorial brain tumour were eligible to participate. We excluded patients with an altered level of consciousness or unstable/deteriorating neurologic status preoperatively, a tumour-related mass effect that the neurosurgeon considered too great for safe participation, baseline subdural pressure $>20 \mathrm{mmHg}$, significant cardiac disease (e.g., left ventricular ejection fraction $<40 \%$, significant valvular disease, pulmonary hypertension), sepsis, hypovolemia, prior lung resection, a history of pneumothorax or prone positioning.

\section{Anesthetic and neurosurgical management}

All participants were monitored in accordance with our typical clinical practice, including noninvasive blood pressure, continuous intra-arterial blood pressure (via the radial artery), end-tidal carbon dioxide, and continuous pulse oximetry monitoring. Monitoring was done using a CARESCAPE $^{\mathrm{TM}}$ Monitor B850 (GE Healthcare Canada, an equilibration period of 120 sec. Subdural pressure (SD) was measured prior to and at the end of each treatment period

Mississauga, ON, Canada). Anesthesia was induced and tracheal intubation was performed at the discretion of the attending anesthesiologist. Anesthesia was maintained with a combination of remifentanil $0.05-0.3 \mu \mathrm{g} \cdot \mathrm{kg}^{-1} \cdot \mathrm{min}^{-1}$ and either sevoflurane or desflurane 0.5-0.7 age-adjusted MAC. Neuromuscular blockade was maintained with rocuronium. Participants' lungs were ventilated with a tidal volume of 6-8 $\mathrm{mL} \cdot \mathrm{kg}^{-1}$ predicted body weight, with the respiratory rate adjusted to maintain a $\mathrm{PaCO}_{2}$ of $32-38 \mathrm{mmHg}$. Predicted body weight (kilograms) was calculated based on previous studies: males $=50 \mathrm{~kg}+0.91 \mathrm{~kg}$. (height in $\mathrm{cm}$ $152.4 \mathrm{~cm}$ ) and females $=45.5 \mathrm{~kg}+0.91 \mathrm{~kg} \cdot($ height in $\mathrm{cm}$ $152.4 \mathrm{~cm}) .{ }^{2,4}$ Prior to the study period and opening the dura, the participants were given mannitol and dexamethasone for clinical indications at the attending neurosurgeon's discretion. Participants were positioned supine or with a lateral tilt, and their head was rotated at the neurosurgeon's discretion. Similarly, the craniotomy incision and removal of the bone flap were performed at the discretion of the neurosurgeon. The study was conducted just prior to opening the dura, at which point, the participant's ventilation parameters and anesthetic levels were maintained at stable levels.

Study participant data

We collected basic data (sex, age, height, and weight) and data about tumour size, type, location, and local mass effect (e.g., presence of midline shift evident on preoperative imaging) from the participant's medical record. The arterial partial pressure of carbon dioxide $\left(\mathrm{PaCO}_{2}\right)$ was calculated from the end-tidal $\mathrm{CO}_{2}$ during each treatment period, and the difference between arterial 
and end-tidal $\mathrm{CO}_{2}$ was determined from an arterial blood gas taken after induction of anesthesia but prior to the study period.

Primary outcome: subdural pressure measurement

Subdural pressure was measured using a previously described technique. ${ }^{8-10}$ A sterile $22 \mathrm{G} / 0.9-\mathrm{mm}$ plastic catheter (Introcan Safety ${ }^{\mathrm{TM}}$, Braun, Melsungen, Germany), connected to sterile fluid-filled pressure tubing and a pressure transducer, was zeroed at the level of the subsequent dural perforation, and the transducer was positioned at the level of the craniotomy opening. The arterial pressure transducer was positioned at the same level. The catheter was introduced tangentially under the dura and into the subdural space along the surface of the brain until the appropriate cardiac and respiratory waves were confirmed. The integrated mean value of the subdural pressure was used to estimate subdural pressure and was recorded electronically every five seconds throughout the study period.

Secondary outcomes: brain relaxation score and cerebral perfusion pressure

The neurosurgeon, blinded to the treatment group allocation, assessed brain relaxation at baseline (after insertion of the subdural pressure monitor but prior to any study intervention) and at the end of each maneuver using a previously described four-point scale $e^{9,11}: 1=$ excellent with no swelling; $2=$ minimal swelling, acceptable; $3=$ swollen but no treatment required; and $4=$ swollen, needing treatment. Cerebral perfusion pressure was calculated based on the difference between subdural pressure and mean arterial pressure (MAP). Mean arterial pressure and heart rate (HR) were monitored continuously via an indwelling radial artery catheter and recorded electronically every five seconds throughout the study period.

\section{Statistical analysis}

We based our sample size calculation on our primary outcome, subdural pressure. Using a previous report on a similar population of patients undergoing resection of supratentorial brain tumours, ${ }^{12}$ the mean (standard deviation [SD]) subdural pressure for patients under general anesthesia was $7.0(5.5) \mathrm{mmHg}$. Assuming a type I error of 0.05 , a type II error of 0.2 , and a two-sided significance testing, a study of approximately 22 patients would be able to detect a difference of $3.5 \mathrm{mmHg}$ in subdural pressure. The definition of a clinically meaningful increase in intracranial pressure is subjective and not well defined in the neurosurgical population; however, previous publications have suggested that increases in intracranial pressure $<3 \mathrm{mmHg}$ are likely clinically insignificant. ${ }^{13-15}$

We used the Shapiro-Wilk W-test to determine the normality of the primary and secondary outcome variables. Changes in subdural pressure, MAP, HR, and brain relaxation score were analyzed similarly and in the following way. We first looked at the overall direction of change for each outcome variable (e.g., increase vs decrease). We then determined the baseline subdural pressure, MAP, and HR as the highest subdural pressure/ lowest MAP/lowest HR recorded during the $30 \mathrm{sec}$ immediately preceding the treatment period. We then determined the highest subdural pressure/lowest MAP/ lowest HR recorded during each 30 -sec treatment period for comparison. Finally, the changes in subdural pressure $(\Delta \mathrm{SDP}), \Delta \mathrm{MAP}$, and $\Delta \mathrm{HR}$ were calculated as the difference between the baseline values and treatment values. The change in brain relaxation score $(\triangle B R S)$ was calculated as the difference between the baseline and treatment values. The $\triangle \mathrm{SDP}, \triangle \mathrm{MAP}$, and $\Delta \mathrm{HR}$ were compared between the two treatment groups (recruitment $v s$ sham maneuver) using a paired Student's $t$ test and Wilcoxon signed-rank test for normally distributed and skewed data, respectively. The $\triangle \mathrm{BRS}$ was compared using the Wilcoxon signed-rank test.

We explored correlations between continuous patient variables (age, body mass index [BMI], tumour diameter, baseline $\mathrm{PaCO}_{2}$ ) and $\Delta \mathrm{SDP}$ during the recruitment maneuver using a Spearman's rank correlation coefficient. We used a Student's $t$ test to analyze the relationship between $\Delta$ SDP during the recruitment maneuver and 1) undergoing the recruitment maneuver first and 2) the presence of midline shift.

All statistical tests were two-sided with a significance level of 0.05. All data analysis was performed with Stata ${ }^{\circledR}$ 12.1 (StataCorp, College Station, TX, USA).

\section{Results}

Twenty-two patients provided informed consent for the study and were randomized during September 15, 2014 to September 2, 2015. The study was abandoned in one participant as the tumour was invading the dura and subdural catheter placement was not reliable. Consequently, 21 patients remained in the final analysis. The characteristics of the study participants are provided in Table 1. Anesthesia was induced in all patients with a combination of fentanyl, lidocaine, propofol, and rocuronium. One participant was maintained on propofol and remifentanil (considered indicated for postoperative nausea and vomiting), and the rest were maintained with 
Table 1 Characteristics of the study population

\begin{tabular}{|c|c|c|c|}
\hline Variable & Overall $(n=21)$ & Recruitment Maneuver & Sham Maneuver \\
\hline Age, mean (SD) & $52(17)$ & & \\
\hline Body mass index, mean (SD) & $27(11)$ & & \\
\hline Tumour diameter $(\mathrm{mm})$ mean (SD) & $35(22)$ & & \\
\hline Midline shift present, $n(\%)$ & $6(29)$ & & \\
\hline Recurrent tumour, $n(\%)$ & $5(24)$ & & \\
\hline Right-sided tumour, $n(\%)$ & $10(50)$ & & \\
\hline \multicolumn{4}{|l|}{ Tumour type, $n(\%)$} \\
\hline Glioblastoma & $2(9.5)$ & & \\
\hline Glioma & $9(42.9)$ & & \\
\hline Meningioma & $6(28.6)$ & & \\
\hline Metastasis & $4(19)$ & & \\
\hline Recruitment maneuver first, $n(\%)$ & $11(52)$ & & \\
\hline \multicolumn{4}{|l|}{ Baseline Measurements } \\
\hline Baseline $\mathrm{PaCO}_{2}(\mathrm{mmHg})$, mean (SD) & & $36(3)$ & $35(3)$ \\
\hline Baseline SDP (mmHg), mean (SD) & & $12(4)$ & $12(4)$ \\
\hline Baseline BRS, median [IQR] & & $2[1-2]$ & $2[1-2]$ \\
\hline Baseline MAP (mmHg), mean (SD) & & $67(8)$ & $67(9)$ \\
\hline Baseline HR (beats $\cdot \min ^{-1}$ ), mean (SD) & & $58(7)$ & $58(7)$ \\
\hline
\end{tabular}

$\mathrm{BRS}=$ brain relaxation score; $\mathrm{HR}=$ heart rate; $\mathrm{IQR}=$ interquartile range; $\mathrm{MAP}=$ mean arterial pressure; $\mathrm{PaCO}_{2}=$ arterial partial pressure of carbon dioxide; $\mathrm{SD}=$ standard deviation; $\mathrm{SDP}=$ subdural pressure

Table 2 Effects of the recruitment and sham maneuvers on outcome variables

\begin{tabular}{|c|c|c|c|c|}
\hline Variable & Recruitment & Sham & Difference $(95 \% \mathrm{CI})$ & $P$ value \\
\hline SDP change, mean (SD) & $4.7(3.6)$ & $0.8(1.8)$ & $3.9(2.2$ to 5.6$)$ & $<0.001$ \\
\hline BRS change, median [IQR] & $0[0-0]$ & $0[0-0]$ & $0(-1$ to 1$)$ & 1.00 \\
\hline MAP change, mean (SD) & $-9.2(7.2)$ & $-0.2(1.5)$ & $-9.0(-12.5$ to -5.6$)$ & $<0.001$ \\
\hline HR change, mean (SD) & $-5.5(5.1)$ & $0.8(1.1)$ & $-6.3(-8.7$ to -3.9$)$ & $<0.001$ \\
\hline
\end{tabular}

$\mathrm{BRS}=$ brain relaxation score; $\mathrm{CI}=$ confidence interval; $\mathrm{HR}=$ heart rate; $\mathrm{IQR}=$ interquartile range; $\mathrm{MAP}=$ mean arterial pressure; $\mathrm{SD}=$ standard deviation; SDP = subdural pressure. SDP and MAP reported in $\mathrm{mmHg}$; HR reported in beats per minute

volatile anesthesia (desflurane or sevoflurane). Fourteen participants $(67 \%)$ received mannitol prior to the study intervention, and all participants received dexamethasone. Baseline subdural pressure, BRS, MAP, $\mathrm{HR}$, and $\mathrm{PaCO}_{2}$ were similar between the two treatment groups (Table 1). The recruitment maneuvers were not abandoned in any participants because of elevated subdural pressure or excessive swelling.

The effects of the recruitment maneuver on the primary and secondary outcomes are summarized in Table 2. The $\triangle$ SDP was significantly higher during the recruitment maneuver than during the sham maneuver (mean difference, $3.9 \mathrm{mmHg}$; 95\% confidence interval [CI], 2.2 to $5.6 ; P<0.001)$ and was reduced to $4.7 \mathrm{mmHg}(95 \% \mathrm{CI}$, 1 to 12 ) during the recruitment maneuver. Median brain relaxation score did not change with either maneuver.
Mean arterial pressure decreased significantly more in the recruitment maneuver compared with the sham maneuver (mean difference, $-9.0 \mathrm{mmHg}$; $95 \% \mathrm{CI},-12.5$ to $-5.6 ; P$ $<0.0001)$. As a result of the increased subdural pressure and decreased MAP, the calculated cerebral perfusion pressure (MAP-SDP) decreased an average of $14 \mathrm{mmHg}$ (95\% CI, 4 to 24) during the recruitment maneuver. Heart rate decreased during the recruitment maneuver when compared with the sham maneuver (mean difference, -6.3 beats. $\min ^{-1} ; 95 \% \mathrm{CI},-8.7$ to $\left.-3.9 ; P<0.0001\right)$. As seen in Fig. 2, the effect of the recruitment maneuver on subdural pressure, MAP, and HR was largely limited to the duration of the intervention.

On further exploratory analysis, the change in SDP during the recruitment maneuver was not significantly correlated with age (robustness of coherence [rho], -0.28 ; 


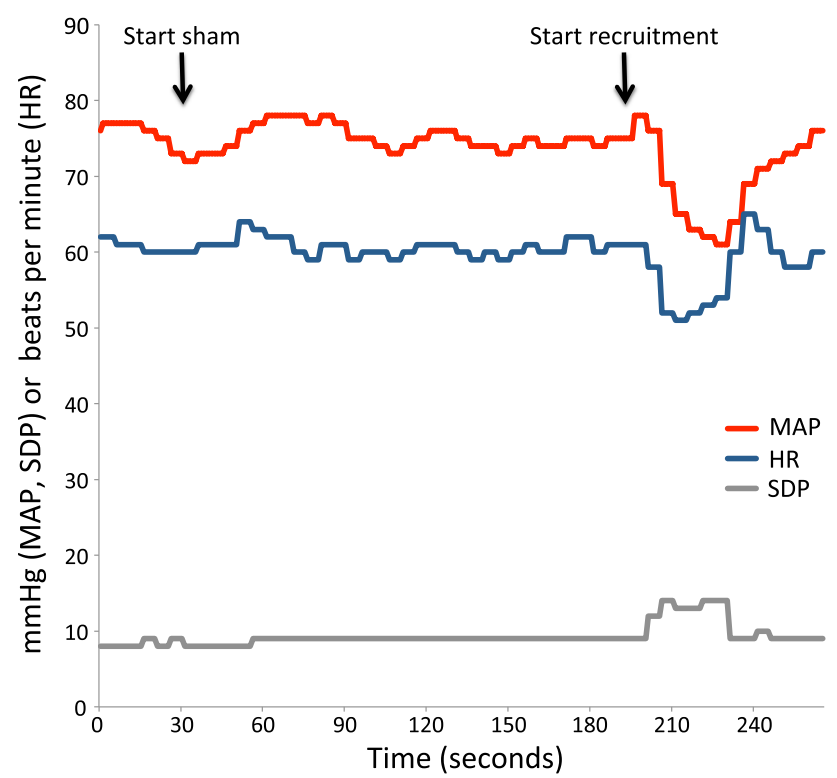

Fig. 2 Illustration of the effects of the sham and recruitment maneuvers on subdural pressure (SDP), mean arterial pressure (MAP), and heart rate (HR) in one study participant

$P=0.28$ ), BMI (rho, $0.14 ; P=0.53$ ), tumour diameter (rho, $0.06 ; P=0.80)$, or presence of midline shift $(P=0.18)$. The increase in subdural pressure during the recruitment maneuver was similar between those who underwent the recruitment maneuver first and those who underwent the sham procedure first (mean difference, $-1.2 \mathrm{mmHg}$; $95 \%$ $\mathrm{CI},-4.5$ to $2.2 ; P=0.47$ ).

\section{Discussion}

Our study presents novel data on the effects of an intraoperative recruitment maneuver in patients undergoing elective supratentorial tumour resection. Our results show that the recruitment maneuver increased subdural pressure and decreased mean arterial pressure and heart rate. Together, these changes resulted in an average reduction in cerebral perfusion pressure of 14 mmHg (95\% CI, 4 to 24), although we did not observe a change in surgeon-assessed brain relaxation score. The long-term impact of this transient reduction in cerebral perfusion pressure should be investigated and weighed against the potential benefits of these maneuvers.

Patients undergoing neurosurgical procedures are at higher risk of postoperative respiratory failure compared with the broader surgical population. A previous study found a nearly threefold increased risk of reintubation and prolonged ventilation in neurosurgical patients compared with the general surgical population. ${ }^{16}$ Furthermore, neurosurgical patients undergoing intracranial tumour resection have an overall $4.4 \%$ incidence of severe respiratory failure or death when undergoing intracranial tumour resection. ${ }^{5}$ Several hypothetical reasons for this increased risk have been proposed, including impaired level of consciousness, prolonged surgical procedures, and the need for prone positioning with airway edema and brainstem dysfunction. ${ }^{5,17}$ Importantly, postoperative respiratory failure is associated with increased mortality, patient morbidity, and resource consumption. ${ }^{16,18,19}$

The clinical benefits of lung protective ventilation have been shown in randomized clinical trials that included regular alveolar recruitment maneuvers in both critically ill and elective surgical patients. ${ }^{3,4}$ Although recruitment maneuvers has been advocated as part of a lung protective ventilation strategy, ${ }^{20}$ the effects of these maneuvers on the cerebral physiology may include an increase in intracranial pressure and a reduction in cerebral perfusion pressure. Determining the precise role of intraoperative recruitment maneuvers in improving patient outcomes is challenging, as clinical trials in the perioperative patient population have included different types of recruitment maneuvers bundled with other interventions (e.g., positive end-expiratory pressure [PEEP], low tidal volume). ${ }^{20}$ The contribution of the recruitment maneuver is difficult to determine; however, the available data suggest that low tidal volumes, rather than PEEP and recruitment maneuvers, are primarily responsible for lung protection. ${ }^{20,21}$ Currently, this uncertain benefit, together with the unclear effects of the transient reduction in cerebral perfusion pressure seen in our study, highlights the need for further investigation into the safety of these maneuvers in the neurosurgical population.

Our results confirm that elective neurosurgical patients experience effects on intracranial pressure (ICP) and MAP during recruitment maneuvers which are similar to those in critically ill brain-injured patients with a closed cranium. A study of critically ill patients with subarachnoid hemorrhage showed a 7-mmHg increase in ICP and a 13$\mathrm{mmHg}$ decrease in MAP during a recruitment maneuver of $35 \mathrm{cmH}_{2} \mathrm{O}$ for $40 \mathrm{sec}^{7}$ The larger magnitude of increase in ICP and reduction in MAP were likely due to the higher pressure and duration of the recruitment maneuver as well as the patient population. Interestingly, another study of neurologically impaired mechanically ventilated patients found a similar increase in ICP $(3 \mathrm{mmHg})$ and reduction in MAP (11 mmHg) using a much higher pressure for their recruitment maneuver $\left(60 \mathrm{cmH}_{2} \mathrm{O}\right){ }^{6}$ Overall, our results suggest that patients with supratentorial brain tumours behave similarly to patients with significant brain injuries when a recruitment maneuver is performed, even if they present electively without evidence of neurologic decompensation. Interestingly, the open cranium/closed 
dura conditions of our study did not appear to attenuate the effect of a recruitment maneuver on subdural pressure, although our study did not directly examine the effect of an open $v s$ closed cranium.

Our study has several limitations. We measured subdural pressure, a surrogate measure of intracranial pressure, and these values may not reflect either the true intracranial pressure-as the bone flap was removed-or the brain conditions when the dura is opened. Similarly, our results do not apply to other contexts, for example, patients with infratentorial tumours, patients in the prone position, other intracranial pathology, or other recruitment maneuver parameters. Patients with more severely reduced intracranial compliance may have greater increases in subdural pressure during recruitment maneuvers. Not all patients received mannitol, and this may have influenced the effects of the study intervention. In addition, we were not able to show a difference in brain relaxation score, although we were underpowered to detect changes in this outcome and assessment may be highly subjective. ${ }^{22}$ Similarly, our study was not powered or designed to detect the relationships between patient variables and magnitude of change in subdural pressure. The two-minute washout period may not have been sufficient to allow all conditions to return to baseline, although we did not observe an effect of treatment order on our primary outcome. Finally, although we showed a significant reduction in cerebral perfusion pressure, we do not know if this finding correlates with long-term clinically meaningful outcomes. This is a potential area for future research.

In conclusion, our study results show that a recruitment maneuver of $30 \mathrm{cmH}_{2} \mathrm{O}$ for $30 \mathrm{sec}$ results in an average increase in subdural pressure of $4.7 \mathrm{mmHg}$ (95\% CI, 1 to 12 ), leading to a mean reduction in cerebral perfusion pressure of $14 \mathrm{mmHg}$ (95\% CI, 4 to 24). Although recruitment maneuvers have recently been advocated as part of a lung protective ventilation strategy in elective surgery, our results suggest that these maneuvers are associated with a transient decrease in cerebral perfusion pressure. Whether this finding correlates with long-term clinically meaningful outcomes is a potential area of future research that should be investigated prior to recommending routine use of these maneuvers.

Acknowledgements The study investigators gratefully thank Dr. Matthias Gorges and Dr. Mark Ansermino for the use of their data collection software. ${ }^{23}$

Conflicts of interest None declared.

Editorial responsiblity This submission was handled by Dr. Gregory L. Bryson, Deputy Editor-in-Chief, Canadian Journal of Anesthesia.
Author contributions Dr. Alana Flexman performed the literature search, designed the study, collected and analyzed the data, interpreted the data, and wrote the first draft of the manuscript. Drs. Griesdale, Gooderham, and Toyota helped design the study, collect the data, and interpret the data, and they contributed to the final version of the manuscript. Ms. Ruth Argue helped collect the data, interpret the data, and prepare the manuscript.

Source of funding This study was supported by a Canadian Anesthesia Research Foundation operational grant. Dr. Alana Flexman was supported by a Vancouver Acute Department of Anesthesia Research Merit Award (Vancouver, Canada). Dr. Donald Griesdale is funded by the VGH \& UBC Hospital Foundation Best of Health Fund.

\section{References}

1. Amato MB, Barbas CS, Medeiros DM, et al. Beneficial effects of the "open lung approach" with low distending pressures in acute respiratory distress syndrome. A prospective randomized study on mechanical ventilation. Am J Respir Crit Care Med 1995; 152(6 Pt 1): 1835-46.

2. Anonymous. Ventilation with lower tidal volumes as compared with traditional tidal volumes for acute lung injury and the acute respiratory distress syndrome. The Acute Respiratory Distress Syndrome Network. N Engl J Med 2000; 342: 1301-8.

3. Amato MB, Barbas CS, Medeiros DM, et al. Effect of a protective-ventilation strategy on mortality in the acute respiratory distress syndrome. N Engl J Med 1998; 338: 347-54.

4. Futier E, Constantin JM, Paugam-Burtz C, et al. A trial of intraoperative low-tidal-volume ventilation in abdominal surgery. N Engl J Med 2013; 369: 428-37.

5. Flexman AM, Merriman B, Griesdale DE, Mayson K, Choi PT, Ryerson $C J$. Infratentorial neurosurgery is an independent risk factor for respiratory failure and death in patients undergoing intracranial tumor resection. J Neurosurg Anesthesiol 2014; 26: 198-204.

6. Bein T, Kuhr LP, Bele S, Ploner F, Keyl C, Taeger K. Lung recruitment maneuver in patients with cerebral injury: effects on intracranial pressure and cerebral metabolism. Intensive Care Med 2002; 28: 554-8.

7. Nemer SN, Caldeira JB, Azeredo LM, et al. Alveolar recruitment maneuver in patients with subarachnoid hemorrhage and acute respiratory distress syndrome: a comparison of 2 approaches. J Crit Care 2011; 26: 22-7.

8. Cold GE, Tange M, Jensen TM, Ottesen S. "Subdural' pressure measurement during craniotomy. Correlation with tactile estimation of dural tension and brain herniation after opening of dura. Br J Neurosurg 1996; 10: 69-75.

9. Gelb AW, Craen RA, Rao GS, et al. Does hyperventilation improve operating condition during supratentorial craniotomy? A multicenter randomized crossover trial. Anesth Analg 2008; 106: 585-94.

10. Tankisi A, Rasmussen M, Juul N, Cold GE. The effects of 10 degrees reverse Trendelenburg position on subdural intracranial pressure and cerebral perfusion pressure in patients subjected to craniotomy for cerebral aneurysm. J Neurosurg Anesthesiol 2006; 18: 11-7.

11. Todd MM, Warner DS, Sokoll MD, et al. A prospective, comparative trial of three anesthetics for elective supratentorial craniotomy. Propofol/fentanyl, isoflurane/nitrous oxide, and fentanyl/nitrous oxide. Anesthesiology 1993; 78: 1005-20. 
12. Rasmussen M, Bundgaard H, Cold GE. Craniotomy for supratentorial brain tumors: risk factors for brain swelling after opening the dura mater. J Neurosurg 2004; 101: 621-6.

13. Lima WA, Campelo AR, Gomes RL, Brandao DC. The impact of positive end-expiratory pressure on cerebral perfusion pressure in adult patients with hemorrhagic stroke (Portuguese). Rev Bras Ter Intensiva 2011; 23: 291-6.

14. McGuire G, Crossley D, Richards J, Wong D. Effects of varying levels of positive end-expiratory pressure on intracranial pressure and cerebral perfusion pressure. Crit Care Med 1997; 25: 105962 .

15. Cooper KR, Boswell PA, Choi SC. Safe use of PEEP in patients with severe head injury. J Neurosurg 1985; 63: 552-5.

16. Arozullah AM, Daley J, Henderson WG, Khuri SF. Multifactorial risk index for predicting postoperative respiratory failure in men after major noncardiac surgery. The National Veterans Administration Surgical Quality Improvement Program. Ann Surg 2000; 232: 242-53.

17. Bruder N, Ravussin $P$. Recovery from anesthesia and postoperative extubation of neurosurgical patients: a review. J Neurosurg Anesthesiol 1999; 11: 282-93.

18. Shander A, Fleisher LA, Barie PS, Bigatello LM, Sladen RN, Watson $C B$. Clinical and economic burden of postoperative pulmonary complications: patient safety summit on definition, risk-reducing interventions, and preventive strategies. Crit Care Med 2011; 39: 2163-72.

19. Linde-Zwirble WL, Bloom JD, Mecca RS, Hansell DM. Postoperative pulmonary complications in adult elective surgery patients in the US: Severity, outcomes, and resource use. Crit Care 2010; 14: P210.

20. Guldner A, Kiss T, Serpa Neto A, et al. Intraoperative protective mechanical ventilation for prevention of postoperative pulmonary complications: a comprehensive review of the role of tidal volume, positive end-expiratory pressure, and lung recruitment maneuvers. Anesthesiology 2015; 123: 692-713.

21. Serpa Neto A, Hemmes SN, Barbas CS, et al. Protective versus conventional ventilation for surgery: a systematic review and individual patient data meta-analysis. Anesthesiology 2015; 123: 66-78.

22. Li J, Gelb AW, Flexman AM, Ji F, Meng L. Definition, evaluation, and management of brain relaxation during craniotomy. $\mathrm{Br} \mathrm{J}$ Anaesth 2016; 116: 759-69.

23. Gorges M, West NC, Karlsdottir E, Ansermino JM, Cassidy M, Lauder GR. Developing an objective method for analyzing vital signs changes in neonates during general anesthesia. Paediatr Anaesth 2016; 26: 1071-81. 